\title{
Ibiza en la pintura costumbrista de Amadeo Roca ${ }^{1}$
}

\author{
Ibiza in the costumbrista painting \\ of Amadeo Roca
}

M. ${ }^{a}$ Lena Mateu Prats

\section{RESUMEN}

La polémica que en los años treinta suscitó la manera con que se mostraba la indumentaria tradicional ibicenca en la pintura costumbrista de Amadeo Roca sirve de eje estructural al artículo para profundizar en el correspondiente concepto de ideal de grupo y en el proceso evolutivo que le afecta. El enfrentamiento entre la corrección establecida (limitada por la pérdida de memoria histórica) y la libertad artística (no exenta de documentación etnográfica y contenido) ofrece así un interesante campo de estudio en el que ha de tomar parte la metodología etnohistórica. Junto a ello, la oportuna estancia del pintor en un núcleo de la payesía isleña, esboza una visión antropológica del lugar y el momento, interrelacionada con el proceso de realización, e incluso desaparición, de parte de su obra.

Palabras clave: Indumentaria tradicional, Ibiza, Pintura costumbrista, Etnografía, Regionalismo.

\section{SUMMARY}

The controversy that aroused in the thirties provoked by the way in which Amadeo Roca represented the traditional costumes of Ibiza in his paintings acts as the structural axis of this article in order to deepen in the appropriate concept of ideal of group and in the evolutionary process that affects it. The clash between established correctness (limited by the loss of historical memory) and artistic freedom (not lacking ethnographic documentation and content) offers an interesting field of study in which ethnohistorical methodology must take part. Beside this the painter's convenient stay in a peasant village of the island sketches an anthropological view of the place and the moment, interrelated with the process of achievement and indeed of disappearance of a part of his work.

Key words: Traditional Costumes, Ibiza, Costumbrista Painting, Etnography, Regionalism.

\footnotetext{
${ }^{1}$ Nuestro agradecimiento a Luis Llobet Tur por la valiosa información aportada sobre Amadeo Roca, así como por permitirnos la reproducción de un óleo (fig. 12) de su colección particular.
} 


\section{APROXIMACIÓN AL COSTUMBRISMO ISLEÑO}

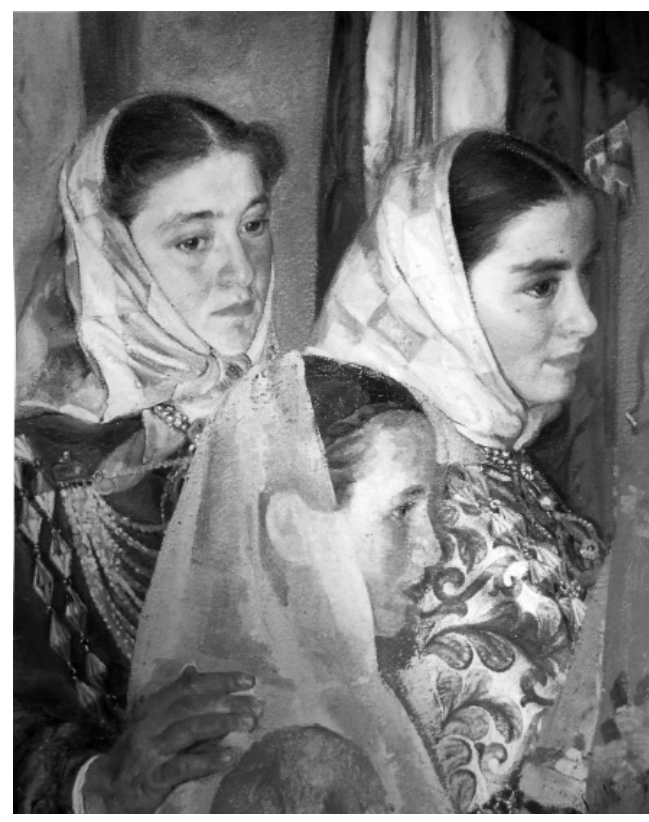

FIG. 1.-Detalle de "Bodas de Ibiza". Amadeo Roca 1933-1936. Museo de Bellas Artes de Valencia.
El pintor valenciano Amadeo Roca (1905-1999) fue uno de los artistas que, a lo largo del siglo XX, se sintió atraído por las figuras populares de Ibiza, donde llegó a principios de los años treinta, contando ya con un considerable bagaje artístico como tarjeta de presentación. El fomento de sus aptitudes en el propio ambiente familiar y el posterior desarrollo de éstas en Roma y Florencia le hicieron lograr en poco tiempo unos objetivos inalcanzables para muchos otros. Y su especial habilidad por reflejar la calidad de los tejidos y adornos de los trajes tradicionales -tomando en un principio por modelos a los de la localidad toledana de Lagartera- le haría merecedor, en 1933, de un importante galardón en Francia, como preludio de su brillante carrera profesional.

En ese mismo año de 1933 se fechan varios de sus dibujos de payesas ibicencas $^{2}$, como producto de la experiencia pictórica que ya por entonces vendría desarrollando en el pueblo de Sant Miquel; donde comenzaría uno de sus óleos más ambiciosos, ya en función del mismo tamaño (2,57 metros de altura por 3 de ancho), y que iría destinado a ser el nuevo embajador de su arte en Francia. Para esta pintura fue necesario que varios vecinos se vis-

${ }^{2}$ Estos coinciden cronológicamente con las fotografías y acuarelas de esta misma temática realizadas respectivamente en la isla por Ortiz Echagüe (Ortiz Echagüe 1971) y por una expedición de alumnos de la Escuela Madrileña de Cerámica (Mateu Prats 2001 y 2010: 35, 37). Si el primero centró su actividad fundamentalmente en la localidad de Sant Jordi durante el mes de abril, aquellos otros lo harían algo más tarde, tomando prácticamente al asalto para el desarrollo de su curso estival el Puig de Missa de Santa Eulària. No sabemos si Amadeo Roca, en un obligado paseo por ese Puig de Missa, tuvo ocasión de intercambiar opiniones con algunos de esos profesores o alumnos. De ser así, dicho contacto le habría permitido observar, a pleno sol, la variada y curiosa indumentaria con que para ellos posaba un nutrido grupo de ibicencos. Algunos de esos trajes literalmente habían salido para tal fin de un pequeño museo local, con el correspondiente permiso de sus gestores; otros lo habrían hecho de antiguas arcas o caixes. Y aunque el principal interés en ese curso de verano fuera el de constatar gráficamente esa vestimenta que se venía considerando en trance de desaparición, las oportunas explicaciones sobre su diferente cronología no eran obstáculo para que, desde el punto de vista meramente artístico, se entremezclasen caprichosamente, jugando con el mayor colorido o sobriedad de unos y otros... Un aspecto de singular relieve, como veremos más adelante, al comentar la labor pictórica de A. Roca en la isla. 

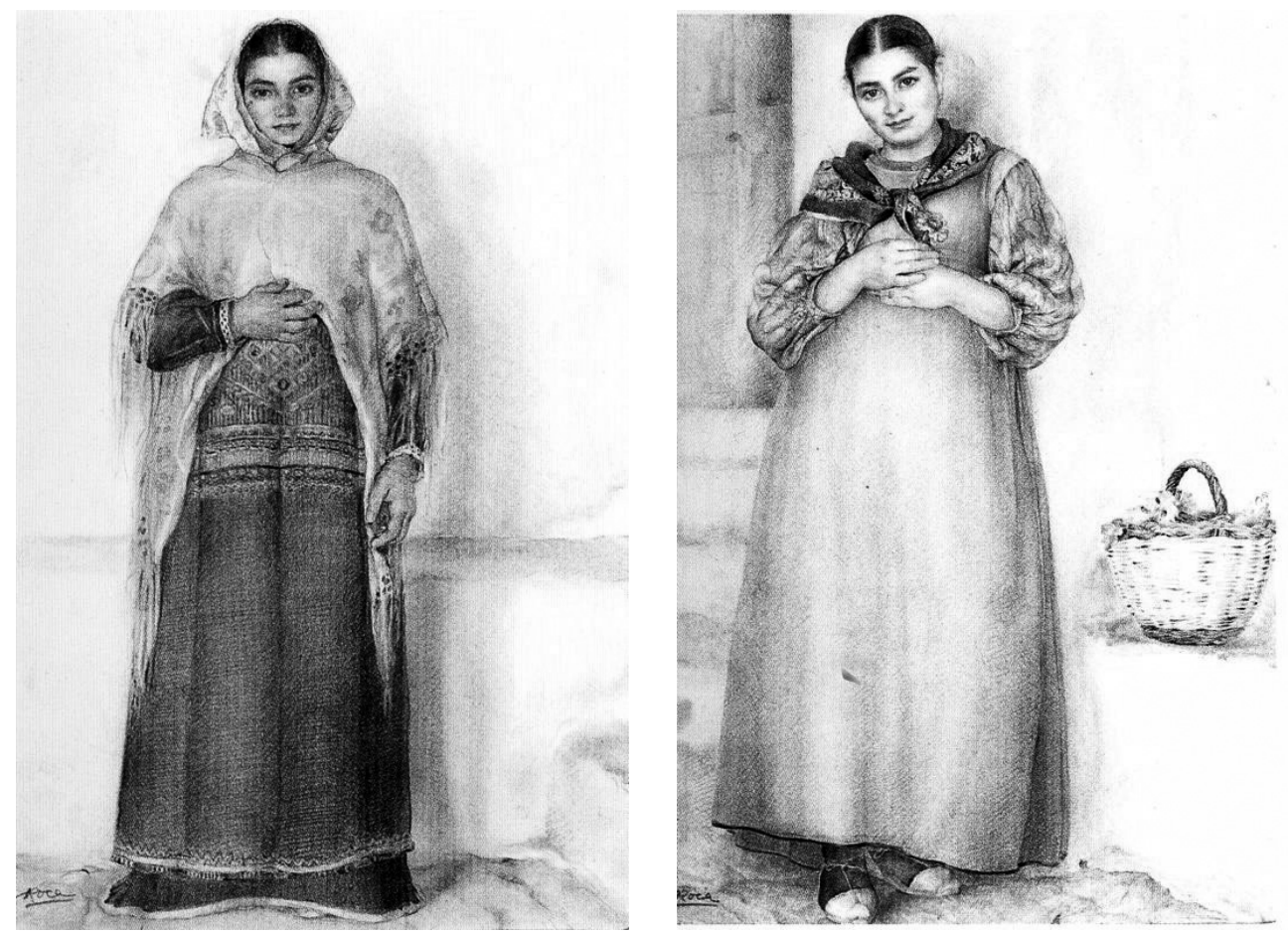

Figs. 2-3.-Dibujos de ibicencas vestidas con la gonella negra (¿1931?) y con el "traje de labor» (1933). Amadeo Roca. Museo de Bellas Artes de Valencia.

tieran al estilo de la payesía, en lo que constituía un muestrario de los trajes usados en distintos momentos históricos, eligiendo como específico escenario el interior de la iglesia y como hilo argumental la celebración de unas bodas.

Pese al alegre revuelo que todo ello supondría para ese pequeño lugar, no faltó quien, a comienzos de 1934, mostrara su disconformidad en el campo etnográfico y muy concretamente en lo concerniente a la indumentaria, trasladando sus quejas a un diario local y aportando así una descripción de las figuras, trajes y objetos allí representados, que podría constituir una valiosa información sobre la génesis de esta obra, en gran parte hoy desaparecida.

Según recogió La Voz de Ibiza, la novia vestía la gonella de color todavía con vigencia social, como a su vez hacía la al.lota o moza que la acompañaba, en ambos casos con emprendada de oro sobre el pecho. Mientras, el novio, al igual que otro joven o "mozalbete" y un hombre de edad madura, llevaban "el traje del siglo pasado"; esto es camisa de "mostra", justet i "ambotonada" ( sic), calçons "de punxa" y espardenyes "de morret" o cerradas en la puntera. Ambos contrayentes se mostraban con sombrero: ella con el de paja de labor y él, con el ceremonioso sombrero de copa (Planells Torres $1934 \mathrm{a}$ y b: 1 y 2).

Consecuentemente, no sólo se establecía una relación diacrónica entre los diversos trajes, sino que además alguno de ellos se configuraba de forma inapropiada, según 


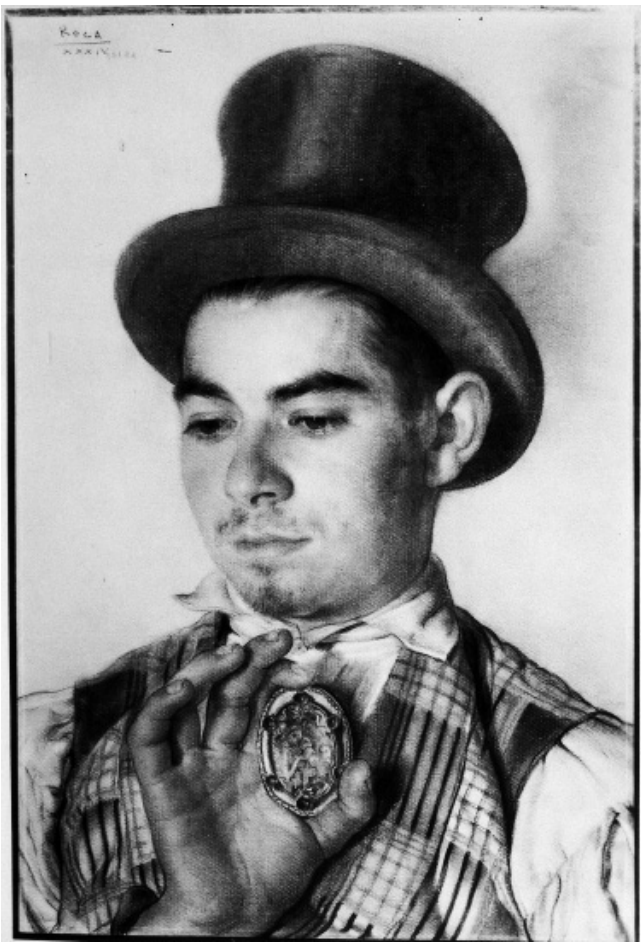

FIG. 4.-Fotografía de un dibujo de Amadeo Roca (1934) obsequiado por el pintor a la familia del modelo. Gentileza V. Ripoll.

las normas establecidas. Evocando, por cierto, cómo se había representado otra pareja en el interior de la iglesia de Santa Eulària, en una de las acuarelas realizadas por la Escuela Madrileña de Cerámica (aunque en este caso la mujer se cubriera con el pequeño sombrero de palma sobre pañuelo que, según Blasco Ibáñez, imprimía un aspecto de pastoras de opereta ${ }^{3}$, y no llevara joya alguna ${ }^{4}$ ).

En este sentido, si a Amadeo Roca pudo haberle sorprendido - como a Joan Amades- la curiosa "etiqueta rústica" de compaginar el sombrero de copa con el uso de alpargatas o espardenyes (Amades 1936: 98), por más que Cataluña contara con un precedente similar en los mossos d'esquadrá, a los ibicencos les causaría estupor que la novia mostrase a un tiempo el referido capell de labor con la emprendada de oro $^{6}$, aunque no tuvieran inconveniente en combinar ésta con las alpargatas. $\mathrm{Y}$ así — tal como igualmente se señalaba-, con la intención de evitar que esa distorsionada imagen pudiera exhibirse en otros lugares como representativa de Ibiza, algún amante del pueblo y sus tradiciones haría llegar dicha disconformidad al aludido diario local.

Sin menoscabo hacia el valor artístico de la aún inacabada obra, en ese artículo también se reprobaba la incorrección de mostrarse el hombre con sombrero en la iglesia. Se señalaba que la indumentaria de éste tampoco era la que propiamente correspondía al referido sombrero de copa (como de hecho ocurriría en otros óleos

${ }^{3}$ Blasco Ibáñez (2007: 90): "Habíase despojado del sombrero de palma con largas cintas, que le daba a las horas de sol un aire de pastora de opereta".

${ }^{4}$ Nos referimos a la realizada por Nieves Martínez con técnica mixta (acuarela y óleo), de $2,90 \times 1,82$ m. ECM no 1106.

5 Su creación, como Escuadra de Paisanos Armados, tuvo lugar el 24 de diciembre de 1721. A mediados del siglo XIX se fijó su vestuario, en el que destacaba el contraste del sombrero de copa y las alpargatas. Ya en 1984, la uniformidad del XIX pasaría a ser la de gala ("mossos d'esquadra. Història". Disponible en www.gen.cat/mossos/cme/historiapdf/historia.pdf; fecha de acceso 7-11-2011). La leyenda popular y poética considera que llevaban una y otra prenda porque en su ideario había la doble voluntad de servir de la misma manera a los ricos que a los pobres.

${ }^{6}$ Desde luego es impensable dicha asociación con el gran sombrero de paja, indicado para las faenas del campo. En lo que se refiere al pequeño capell de palma, existen algunas fotografías que la constatan — tal como pensamos exponer con más detalle en un próximo estudio-, enfrentándose asimismo con la generalizada opinión isleña. 
de A. Roca, y en lo que quizá sería el dibujo previo de otra opción pictórica, en este caso sin disponer el jaquetó sobre un desconcertante jupet $i^{7}$ ), y que nunca se había visto en Ibiza mujer alguna enarbolando la bandera o estandarte parroquial.

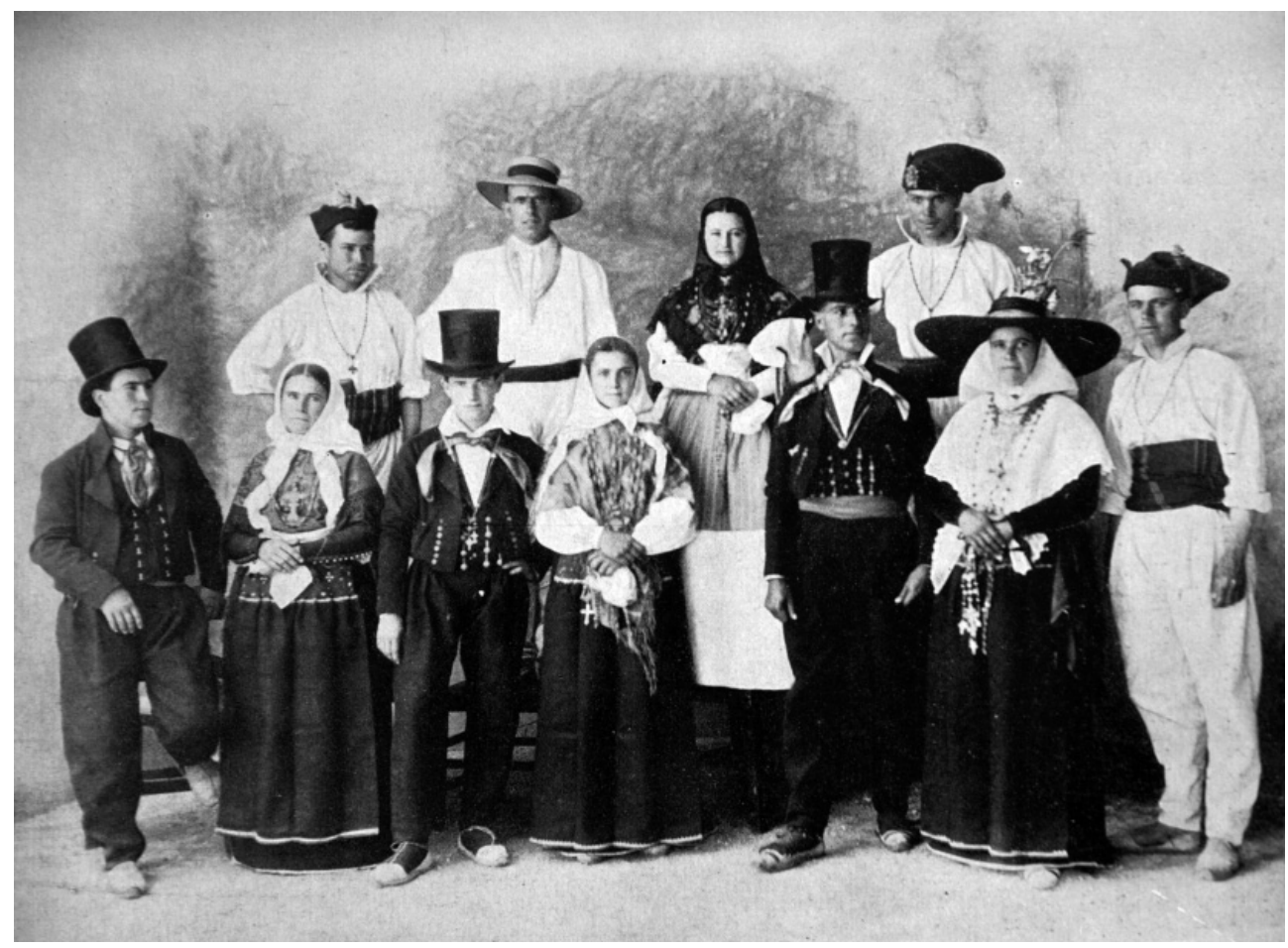

FIG. 5.- "Grupo de campesinos con el antiguo traje típico de las Pythiusas, premiado por la Sociedad Arqueológica Ebusitana en las Fiestas del Centenario del marino Riquer". Fotografía de C. Bertazioli ${ }^{8}$ (Román 1906: Lám. XL).

En realidad, los mismos ibicencos habían protagonizado una polémica en cierto modo parecida treinta años atrás. Concretamente cuando, con ocasión de la visita de Alfonso XIII a la isla en 1904, el Ayuntamiento de la ciudad solicitó a las corporaciones municipales del campo que acudieran al recibimiento del monarca con sus respectivas "banderas parroquiales" y una representación del traje "típico de los campesinos" en "sus diferentes épocas" (Anónimo 1904a: 1). A esta llamada, la corporación de Sant Josep

${ }^{7}$ Dicho jupetí y especialmente el que muestra uno de los modelos de Bodas de Ibiza (fig. 6), traen a la mente el que describiera V. Ferrer Saldaña, en 1868, de seda y grandes cuadros de colores fuertes, con dos hileras de gruesos botones de filigrana de plata (Llobet 2003: 72-73; Mateu Prats, en preparación).

${ }^{8}$ Otra de las imágenes incluidas en el libro de J. Román (Véase nota 13) se reproduce y reconoce también como de C. Bertazioli (Llobet Tur 2003: 75), junto con algunas más en las que figuran, en número de tres o emparejados (ibid: 60, 65, 70, 80 y 85), los mismos miembros del referido grupo de campesinos premiado en 1906 por la Sociedad Arqueológica Ebusitana. 
contestaría — siendo secundada posteriormente por las restantes - que las primeras únicamente eran propias de las procesiones religiosas y los segundos «bueno[s] ya sólo para exposiciones arqueológicas y fiestas carnavalescas" (Anónimo 1904b: 2). Dos años después, ellos mismos se mostrarían coherentes con esos conceptos en la práctica, al presentarse a un concurso convocado por la Sociedad Arqueológica Ebusitana, del que resultarían ganadores por sus mencionados trajes "típicos", entre los que se contaba la antigua gonella negra y el masculino complementado con sombrero de copa (Anónimo 1906a: 1; Anónimo 1906b: 1-2; Román 1906: Lám. XL).

Esos trajes son también los que, en mayor o menor medida, documentamos en la producción fotográfica y pictórica de Narcís Puget, el llamado patriarca de la pintura ibicenca, tal como ocurre en el lienzo que presentó al concurso nacional de pintura sobre el traje regional en el mismo año de 1934 en que se publicaron los artículos tan duramente dirigidos a Amadeo Roca ${ }^{9}$. Sin embargo, el mismo cronista que los firmaba al referirse a esta otra obra, simplemente se limitaría a cuestionar la gestualidad de una de las figuras, sin recriminar a Puget ningún desajuste cronológico (Planells Torres 1934c: 1), seguramente por ceñirse éste a las normas reconocidas en la indumentaria tradicional y al correcto emparejamiento de ambos sexos, sin recrear vivencia o episodio alguno.

\section{CODA ETNOGRÁFICA A LAS “BODAS DE IBIZA"}

En todo caso, en esas "Bodas de Ibiza" extraña, ya en principio, que A. Roca hubiera emparejado a la mujer vestida con la moderna gonella de color con el hombre vestido al estilo del siglo XIX, cuando tenía perfecto conocimiento de la antigua variante femenina que propiamente correspondía a aquel. Así se comprueba en uno de los citados dibujos (al parecer de 1931), expresamente dedicado al traje de gonella negra (fig. 2) y se corrobora en una fotografía ( $\sin$ fecha determinada), justamente relacionada con ese óleo en particular, y en la que dicha gonella aparece además asociada al correspondiente traje masculino (fig. 6). Esta circunstancia fundamentalmente plantea la doble posibilidad de que esas notas en la prensa tal vez transmitieran una información confusa, o que, por el contrario, la fotografía respondiera a una nueva selección indumentaria, como dúctil rectificación por parte del pintor.

En esa instantánea podemos reconocer al mismo Amadeo Roca junto a tres de los modelos con que contó para dicha obra y entre los que destacan los que serían los novios protagonistas de la escena, con coherencia cronológica en su indumentaria: ella con cambuix en la cabeza y la referida gonella negra de grueso burell; él con los calzones del mismo color y género, así como con jaquetó o chaqueta corta y sombrero de copa. No sabemos si en la consiguiente representación pictórica el novio seguiría luciendo este sombrero, lo habría depositado en algún banco o mesa de altar — tal como se recriminaba en ciertas disposiciones eclesiásticas a los mismos ibi-

\footnotetext{
9 "Entre otras cosas dice la carta que en el pueblo [de donde ella procede, se entiende] hay un señor pintor que lleva ya varios meses trabajando en un cuadro de grandes proporciones que, de no ser un absurdo, sería una gran realidad. Bastante adelantada la obra pictórica, aparece en el lienzo una boda" (Planells Torres 1934a: 1).
} 
$\operatorname{cencos}^{10}$-, o lo llevaría bajo el brazo..., tras haberse destocado debidamente en el interior de la iglesia.

La mencionada fotografía asimismo parece traslucir la dificultad que en esos momentos ya habría existido a la hora de localizar las oportunas prendas-testigo, pese a contar, por ejemplo, con un asesor etnográfico de la talla de A. Marí Ribas "Portmany" ${ }^{11}$. Aunque la al.lota viste la antigua gonella negra, ya no dispone sobre el cambuix el sombrero de enorme ala y penacho de flores ${ }^{12}$ que formaba parte del considerado - en alguna ocasión - antiguo "vestit de núvia" de la payesa ibicenca ${ }^{13}$, como tampoco exhibe emprendada o conjunto de joyas sobre el pecho. Al tiempo que para el hombre no se aprecia botonadura sobre su chaqueta o jaquetó (bajo el que sí asoman los botones colgantes de filigrana y plata de una de las hojas delanteras del chaleco $)^{14}$. Detalles que, especialmente en el segundo caso, podríamos imaginar que serían subsanados por Amadeo Roca en la plasmación pictórica.

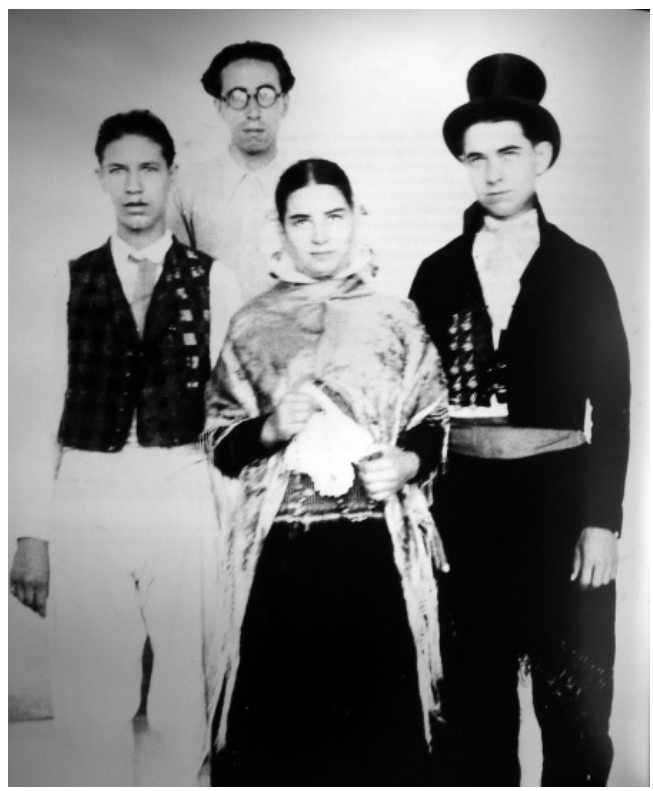

FIG. 6.-Amadeo Roca posando con algunos de los modelos de "Bodas de Ibiza" (Amadeo Roca. Generalitat Valenciana-Museu de Belles Arts de València 2008: 86).

${ }^{10}$ En las Instrucciones de Juan Lario, de 1760, se decía: “Deseando evitar la irreverencia con que entran algunos en el templo, llevando redes, y la falta de devoción con que muchos están en la Iglesia y oyen la Misa, reclinados sobre bancos y mesas de altares, poniendo aun sobre ellos los sombreros y gorros..." (Citamos por Marí 1984: 68).

${ }^{11}$ Nuestra gratitud al profesor A. García Ninet por facilitarnos el acceso a su archivo particular sobre la polifacética figura de A. Marí Ribas "Portmany" (Ibiza 1906-1974), excepcional dibujante que también negoció con antigüedades, muy especialmente del mundo tradicional ibicenco, y que así llegó a conformar una importantísima colección etnográfica con la que estaba previsto crear un museo (contando con apoyos como el del Marqués de Lozoya, uno de sus avales en el campo artístico).

${ }^{12}$ En el archivo citado en la nota anterior se conservan, entre otros varios documentos, tres cartas relacionadas con el Museo del Pueblo Español (23-1-1965, 12-1-1965, 5-2-1965), una de ellas firmada por el Marqués de Lozoya y las otras dos por Nieves de Hoyos, solicitando a "Portmany" información etnográfica, así como, precisamente, otro sombrero de fieltro "con ramo", por estar ya muy viejo el procedente de la Exposición de 1925. Esta solicitud sería atendida enviando el ejemplar que se conserva hoy, sin fecha de ingreso, en el Museo del Traje (CEO42520), según se deduce de los datos expuestos.

${ }^{13}$ Publicado por el Institut Gallach 1927: comentario a la tercera figura de "Tipos ebusitanos". Agradecemos a Marcos León Fernández la información aportada. En alguna ocasión esta imagen se ha atribuido al fotógrafo Mas y a los años 20 (véase, no obstante, la nota 8).

${ }^{14}$ Con fecha 23-1-1965 el Marqués de Lozoya escribía a "Portmany": "Me telefonean del Museo del Pueblo Español diciéndome que necesitan un traje de novio ibicenco, para hacer pareja con 
A este respecto conviene tener presente que a principios del s. XX sólo en Formentera, por su mayor ralentización en el vestir, V. Navarro pudo recoger testimonios del referido sombrero con alto penacho de flores y plumas (Navarro 1901: 158); el mismo que habrían llevado las ibicencas a mediados del siglo anterior ${ }^{15}$, en íntima asociación con la emprendada de plata y coral. No obstante, la investigación de indumentaria antigua llevada a cabo en el pueblo de Sant Josep en 1906 por Pere Marí "Cala", a que antes hacíamos referencia, lo habría sacado nuevamente a la luz (Mateu Prats 2011b: 22-26), de modo similar a como ocurriría en 1925, con motivo de la Exposición del Traje Regional celebrada en Madrid (Mateu Prats 2012: 74, figs. 4 y 5) y quizá incluso en los años $60^{16}$, gracias al "Mestre Albert” y al propio A. Marí Ribas "Portmany", respectivamente.

De esta forma, en términos generales podríamos datar el modelo femenino recogida por Roca — simplemente con cambuix y mantón con largas puntas abiertas - a principios de los años sesenta del siglo XIX, cuando ya era usual mezclar en la emprendada —aquí ausente- la plata y el coral con el oro (Flores 1861: 89-90), como paso previo a la imposición de éste; un momento de transición captado en una fotografía de Clifford ${ }^{17}$, en la que el hombre también se muestra con el traje reproducido por Roca, aunque portando barret en vez del señalado sombrero de copa.

Más moderno sería, en cambio, otro de los trajes representados en esas "Bodas de Ibiza": la gonella de color, por entonces todavía con vigencia social entre las payesas, por más que ya fueran muchas las que iban abandonándola para vestirse de «balandras", tal como se denominaba en la isla a las que seguían los cánones indumentarios de la ciudad ${ }^{18}$. La gonella en cuestión era vista por los amantes del mundo tradicional con rasgos arcaizantes o como compendio de distintas culturas, tal como en este último sentido se pronunciaba José Costa "Picarol" en una nota periodística, movido

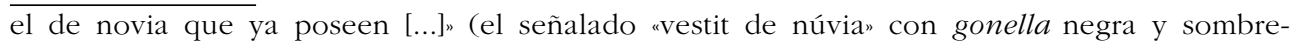
ro). Poco antes, 12-1-1965, lo había hecho Nieves de Hoyos en los siguientes términos: "Me decía Vd. que tenía un traje de Ibiza de novio a falta de los botones de plata del chaleco $[\ldots]$.

${ }^{15}$ Claessens (1858: 19): "Ella lleva en su cabeza [...] un sombrero negro descomunal cual el abierto de clérigo; y mucho mayor que el sombrero de los aragoneses. Su copa reducida está adornada con cintas, ó galones de oro, y en la parte posterior hay un plumaje ó ramo de flores de los colores todos, pero especialmente de rosas, atributo mas natural de la belleza de la mujer, ó donzella de los campos". Este tipo de sombrero ya se constata, sin penacho, a principos del s. XIX en las pinturas murales de Sant Miquel y en un grabado de J. Cambèssedes (Mateu Prats 2012b: 138). Y a él se referiría el Archiduque Luis Salvador en 1867 —también sin mencionar penacho alguno-, considerándolo ya una prenda anticuada que por entonces sólo conservaban en Ibiza las ancianas como recuerdo de su juventud (Luis Salvador 1869-1891, ed. de 1982: 36 y 283-284. Véase Mateu Prats 2009: 215, nota 844).

${ }^{16}$ Véase nota 12.

${ }^{17}$ Fotografía de Charles Clifford perteneciente al Patrimonio Nacional. Al igual que el testimonio escrito de A. Flores, se corresponde con el viaje realizado por la reina Isabel II a las Baleares en 1860.

${ }^{18}$ "iMalditos los dioses a quien trate de proscribir ese hermoso traje (de gonella de color) para vestir a nuestras campesinas de 'balandras' (como llama aquí el pueblo a las vestidas desgarbadamente con el traje ciudadano), y apiádese el Dios verdadero del gran delito de lesa patria y lesa moral, y leso arte, cometido por quienes, con un extravío superior a todo comento, procuran suplantar con el torpe baile 'agarrado' el típico danzar de la tierra! [...]" (Verdera 1925: 2). 
por la intención de frenar su progresivo abandono, y entre cuyas evocadoras comparaciones destacaba la sugerente imagen de Gioconda que decía proyectaba la propia campesina ibicenca, con su decorosa pose y sonrisa (Picarol 1931: 1).

\section{UNA VISIÓN PROFUNDA SOBRE LA MUJER IBICENCA}

El hecho de que tales apreciaciones se fechen en 1931 nos lleva a preguntarnos si incidieron de algún modo en otra producción de A. Roca - realizada tres años más tarde-, en la que se muestra el busto de una payesa como una recreación de esa célebre obra. Con la gestualidad contenida representativa de las ibicencas, la citada campesina se limita aquí a alzar su mano izquierda hacia el rostro - como en una fugaz ruptura del estático posado-, en lugar de mantenerla bajo la derecha como hace aquella otra, y tal como tradicionalmente ha venido haciendo la mujer ibicenca (fig. 2) ${ }^{19}$. Convergiendo así el modelo cultural implantado en la isla con la inclinación clasicista del pintor.

De hecho - recordando lo señalado por A. Martínez García sobre la Gioconda (2006: 140)—, algo muy importante en la composición del retrato renacentista era el decorum (es decir, lo apropiado, lo pertinente) de quien posaba, máxime si se trataba de una mujer;

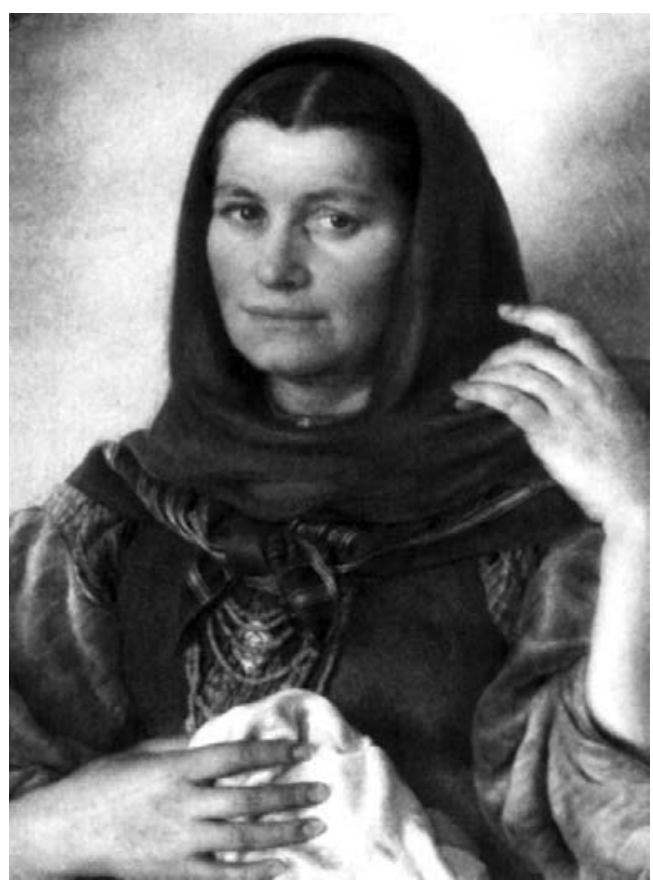

FIG. 7.—Payesa", 1934. Estampa. Colección de Asunción Seco. Amadeo Roca. Generalitat Valenciana-Museu de Belles Arts de València 2008: 183). motivo por el que los gestos, ademanes y expresiones estaban muy limitados: El rostro sereno, el porte erguido, las manos sosteniendo un pañuelo, descansando sobre los brazos de un asiento, o permaneciendo unidas como señal de modestia..., eran los códigos gestuales con que se expresaba la honesta virtud de la retratada. Es decir, tal y como plasmó Roca a la mujer ibicenca en ésta y otras ocasiones, complaciéndose en su natural compostura. En este caso en concreto, materializando con los pinceles la que - a juzgar por un tercer y tam-

19 Tal como ya hemos recogido en otras ocasiones (Mateu Prats 2009: 222, nota 871 y 2011a: 38), a este respecto es significativo que el Decor puellarum - un tratado de moral femenina publicado en Venecia en 1471 - , recomiende a las jóvenes, tanto si están caminando como paradas, que mantengan siempre la mano derecha sobre la izquierda a la altura del talle. Esto es, "algo que cumple escrupulosamente Lisa del Giocondo en su honestidad y virtud de la retratada" (Martínez García 2006: 3, 140). Véase también Allen (2006: 659-660). 
bién representativo ejemplo ${ }^{20}$ — sería una percepción de generalizada o singular aceptación en la isla.

Todo ello viene a realzar la dignidad con que las mujeres del mundo rural aparecen en la producción del artista. Aunque - como en la presente obra-, puedan mostrarse humildemente vestidas con el traje de labor, el autor profundiza en la expresión de sus ojos (donde decía que reside el alma o pathos) o recoge sus facciones más definitorias (aunque sin romper su instintiva búsqueda de la belleza) con el mismo esmero que dedicaría al más ilustre de los modelos. Siendo este respetuoso y democrático tratamiento uno de los rasgos que particularizan a Roca entre los pintores del género costumbrista.

De acuerdo con esto último, Roca presta también una meticulosa atención a los tejidos y adornos populares, fundamentales en la temática regionalista, a pesar de que ésta ya se hubiera alejado del afán caracterizador que en principio pareció guiar este tipo de pintura (Pérez Rojas y Alcaide 1998: 73). Se trata de una circunstancia que podría explicar la conjugación de objetividad y "licencia pintoresca" que se ha mencionado para algunas de sus obras (ibid.), y que habría sido el desencadenante en Ibiza de la airada polémica a que antes hicimos referencia.

Contemplando por ejemplo a la mencionada payesa, tenemos que comenzar por reconocer al pintor el mérito de haber plasmado unos hilos de coral prácticamente olvidados, aunque su disposición sobre un traje de labor resulte hoy cuando menos chocante, por totalmente desconocida. Un desconocimiento que, en todo caso, no nos permitiría cuestionar dicha asociación, vigente al menos hasta hace relativamente poco tiempo en otros lugares, en función del carácter mágico-protector que se venía atribuyendo a este tipo de objetos (tal como la documentación demuestra en el pasado de Ibiza), más allá del valor meramente ornamental que puedan revestir bajo nuestra perspectiva actual.

Sin embargo, es el propio Roca, al vincular una prenda de oro con un conjunto similar, el que nos alerta sobre los difuminados límites entre su interpretación del costumbrismo isleño (con la libertad artística de un gran pintor) y la realidad. Nos referimos al dibujo en que se asoma risueña la que fuera su modelo predilecta ( $n a$ Margalida de Can Taronges), luciendo una ostentosa "joia" de ese metal directamente sobre el cos de la gonella de color, como si dicha alhaja — todavía vigente en esos momentos- constituyera una honrosa condecoración, de connotación religiosa, a la dulzura con que desempeñaba sus cotidianos quehaceres. Esto es, tal como en la práctica vendría siendo costumbre en la isla ${ }^{21}$, con independencia de que las muchachas ya lucieran las joyas sobre los mantones de gala o festivos.

\footnotetext{
${ }^{20}$ A propósito, el fotógrafo croata Mario von Bucovich (1934: 383) llegaría a manifestar — después de referirse a la "belleza serena y casi bíblica" de la mujer de Ibiza-, que en muchas ocasiones había adivinado en los rostros la misteriosa sonrisa de la Gioconda: "Y yo ya he entendido la razón de esta sonrisa legendariamente misteriosa. Tal misterio no procede del alma pura de la mujer admirada, sino de lo ignoto de una raza cuyo original ancestral se refleja en los movimientos imperceptibles de los labios y en la expresión indefinible de esos ojos que os miran" (citado en Valero 2008: 28-29).

${ }^{21}$ "Sabido es [...] que para las jóvenes payesas, la joya prometida por sus padres es un estímulo que fomenta su afición a las faenas agrícolas" (Anónimo 1884: 1). Se refirieren por lo general al conjunto de la cruz, al que las más acomodadas añadirían el de la “joia" propiamente dicha.
} 
En realidad, son muchas las preguntas que plantean las figuras tradicionales de Ibiza plasmadas por Roca, como aparente y polifacético resultado de la documentación etnográfica, del sentimiento artístico y de la intención simbólica, siendo necesario volver a subrayar que esas dos últimas connotaciones no excluyen, necesariamente, la fidelidad con respecto a una realidad del pasado más o menos lejano.

Una de esas interrogantes es la que queda de nuevo en el aire al advertir la presencia del cambuix, en lugar del más moderno pañuelo de cabeza, en el dibujo que acabamos de comentar. Se trata de una toca que propiamente habría desaparecido junto con la antigua variante de la gonella negra, pero que quizá continuara vigente, ocasionalmente o no. Al menos de esta forma se atestigua en la producción pictórica de Laureano Barrau, acompañando los más humiles trajes de diario o labor (Sa Nostra 1996b: $28^{22}$ ), dejando aparte su asociación incluso con la festiva "gonella o faldelli de color blanco que muestra una modelo del - como decíamos- patriarca de la

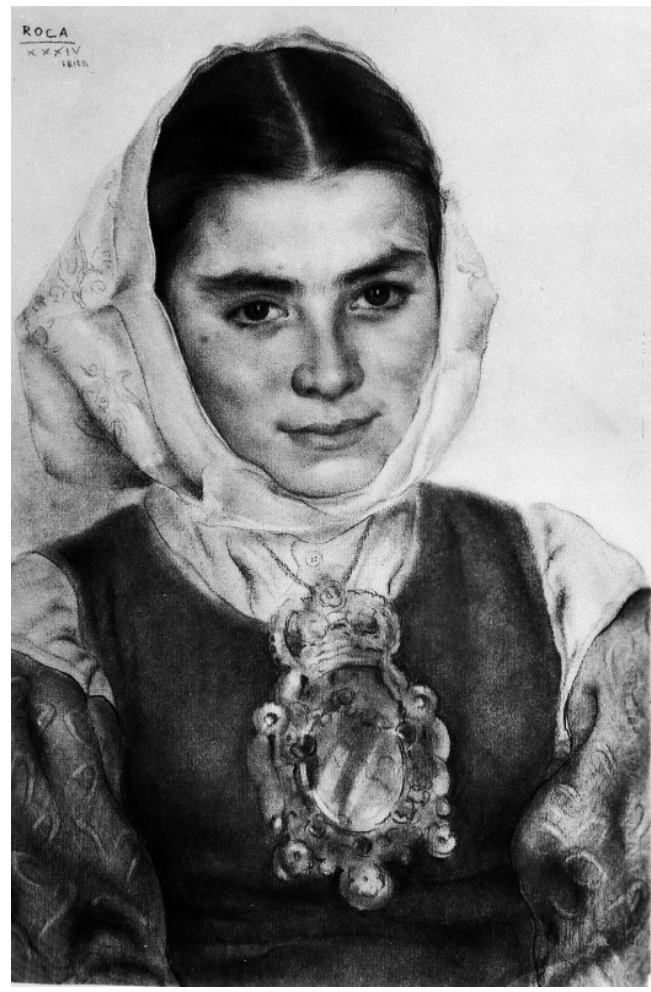

FIG. 8.-Fotografía del dibujo (1934) obsequiada por Amadeo Roca a la familia de la modelo. Gentileza V. Ripoll. pintura ibicenca, Narcís Puget (Sa Nostra 1996a: 39, fig. $23^{23}$ ).

Sea como fuere, aquí optamos por suponer que A. Roca, tanto en éste como en algún otro caso, básicamente pretendería ofrecer una atractiva imagen tradicional de la isla, con impronta de antigüedad y las mencionadas connotaciones. Y es en este sentido en el que tendría la capacidad de resucitar o insuflar una nueva vida a algunas de las joyas y ropas que formaban parte, guardadas en viejas caixes o arcas, de ya incompletos conjuntos indumentarios. Muchos de los cuales, en una lamentable paradoja, pasaban literalmente a las manos de esos artistas, como quizá la mejor opción de venta para los campesinos, pensando en los beneficios turísticos que reportaría a la isla su reiterada reproducción en los lienzos (Anónimo 1934: 2).

${ }^{22}$ Concretamente lo porta la niña que aparece leyendo, junto a un grupo de mujeres que bordan, en una escena interior. Dones cosint, óleo realizado hacia 1920. Colección Galería Manuel Mayoral, Barcelona.

23 Se trata de una instantánea en la que aparece el mismo Narcís Puget, retocando el atuendo de una modelo, tal vez con el propósito de recoger luego ese tocado en un cuadro o fotografía. 


\section{LA PERCEPCIÓN DEL HOMBRE IBICENCO}

Ya veíamos que el temor a que esa plasmación pictórica no ofreciera una imagen real de la indumentaria tradicional llevada en la isla fue uno de los factores desencadenantes de la crítica que saltó a la prensa en 1934, salpicando la reputación de Roca. La reprobación se fundamentaba en la peculiar forma con que asociaba diversas prendas en un mismo conjunto o modelo indumentario.

Sin repetir lo ya expuesto, es de resaltar como constante en los testimonios conocidos de su producción artística, la presencia del sombrero de copa en detrimento del más generalizado barret, incluso con independencia de la corrección indumentaria establecida. Probablemente — pensamos - con la intención de introducir un elemento que viniera a potenciar su particular visión del payés ibicenco.

Lejos de perseguir que sus óleos y dibujos fuesen un espejo más del costumbrismo local, intentaría reflejar una percepción emocional de los tipos populares, como ya hemos señalado al referirnos a la mujer. Si bien, en el caso del hombre, esa visión o realidad interior no vendría a coincidir, como aquella, con la generalmente aceptada entre los isleños, provocando que alguno de ellos considerara su arte propio del absurdo (Planells Torres $1934 \mathrm{a}$ y b: 1-2 y 1). Esto es, englobándolo bajo la etiqueta de otras tendencias artísticas más vanguardistas — en nuestro país asociadas a este tipo de pintura regionalista-, y que tendrían su proyección o resurgirían posteriormente, en el campo literario, con el llamado "teatro del absurdo". En este sentido, resulta ilustrativa la lectura de los signos que se han reconocido en la famosa obra de Miura precisamente titulada Tres sombreros de copa, donde dicho sombrero no tiene un valor sustantivo, sino de disfraz (Canoa Galiana 2006), en función de su oscilante carácter, desde ceremonial a circense. Tal vez también influía el valor relativo de las convenciones sociales que representa en el mundo burgués, y que al ser adoptadas por la payesía eran aún más susceptible de contemplarse desde un ángulo más crítico.

Puede que desde esta perspectiva, y con la penetración psicológica que le caracterizaba, Amadeo Roca se encargara de coronar con dicho capell de copa a uno de los modelos culturales de la isla, como es el "L'Herew", destacando así la situación dominante que consuetudinariamente éste adquiría con respecto a su propia madre. Una situación preeminente que, a su vez, era remarcada por la postura, más de arrogancia que de amparo, con que dicho "heredero" se muestra al lado de la anciana, con la que a su vez contrasta, en blanco y negro, como representantes de dos mundos contrapuestos.

En lo concerniente al aspecto indumentario $-\mathrm{y}$ abriendo un paréntesis en este apartado-, dicha mujer nos ofrece una bella y desconocida representación de la gonella negra, que, como una Dolorosa, nos sorprende con el manto de la viudez o plor, y por la manera con que anuda un gran mocador o pañuelo blanco bajo la barbilla, con la misma vuelta hacia delante que a veces conformaba en los hombres el nudo de su corbata o chalina —según nos señala F. X. Torres i Peters. Como licencia artística que rompe el duelo, tan sólo destaca - precisamente sobre su seno materno- la mostra bordada y polícroma del davantal, al tiempo que la ausencia de joyas sobre el pecho pasa desapercibida bajo las largas puntas del pañuelo de cabeza.

Curiosamente, es en el cuadro titulado El bisbe - de fecha muy posterior-, donde Amadeo Roca plasmaría con perfección de detalle la emprendada de plata y coral 


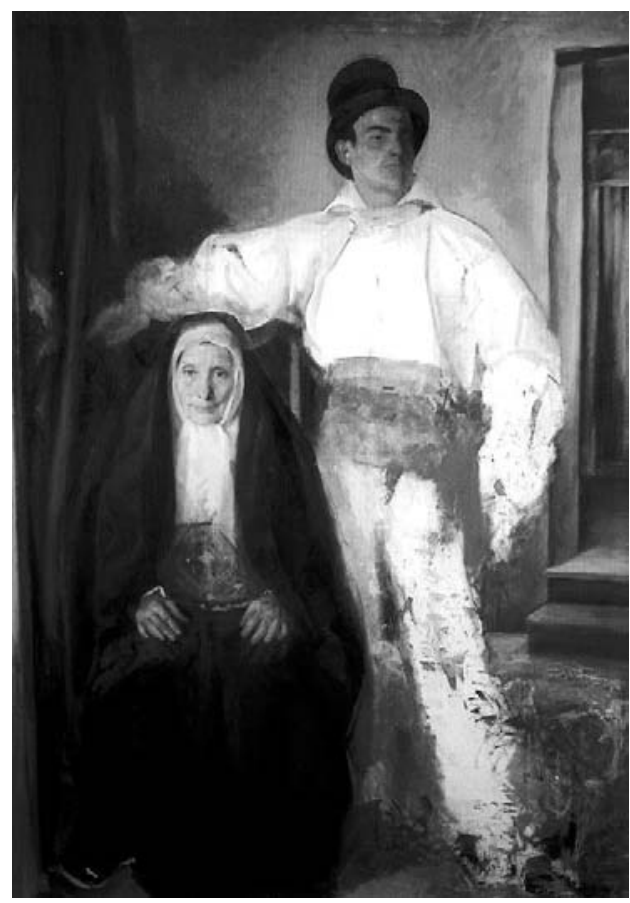

FIG. 9.— "L'hereu", iniciado por Amadeo Roca en 1936. Museo de Bellas Artes de Valencia.

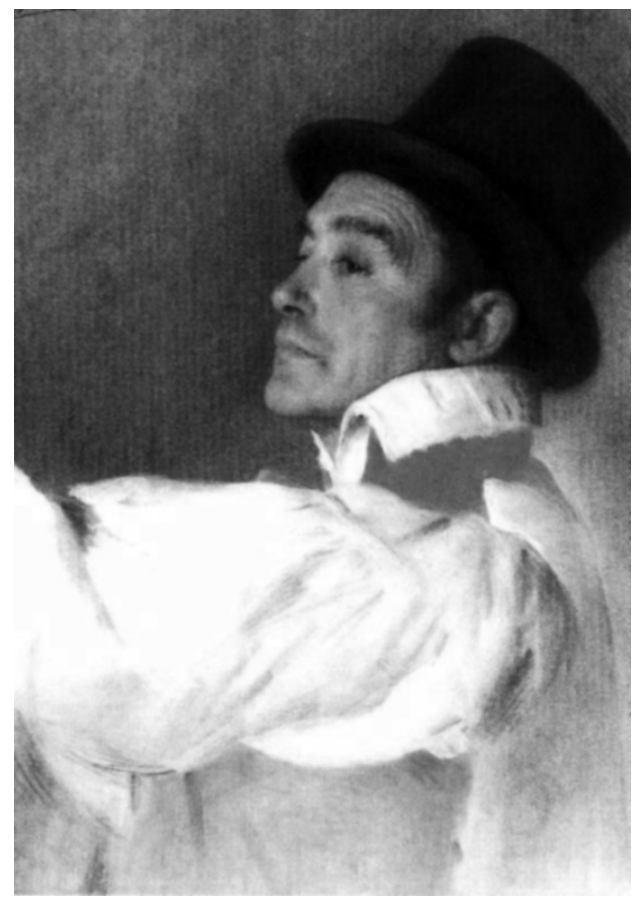

FIG. 10._- "Terin con traje ibicenco", fechado en 1950. Museo de Bellas Artes de Valencia.

(configurada por un rosario al parecer concebido para llevarse como pectoral) que es exclusiva de la gonella negra. Por más que, en ese caso en concreto, aparezca dispuesta sobre el pecho de un hombre igualmente vestido con la camisa de drap del payés ibicenco y faja morada de obispo, ya en conformidad con la denominación que se da al retratado. Esta obra tal vez tenga una intencionalidad simbólica más allá de nuestro alcance, pero también ha permitido pensar a Torres Peters que pudiera tratarse de la representación de algún personaje peculiar de la isla.

En todo caso, tanto dicho "bisbe" como el referido "hereu" son dos ejemplos a tener en cuenta a la hora de considerar la manera en que, al menos en un primer momento, Roca pudo plasmar al protagonista masculino de las Bodas de Ibiza. En esa ocasión —atendiendo a lo recogido en la prensa-, con jupetí o chaleco de rica botonadura sobre camisa de mostra, calçons de punxa y espardenyes "de morret", además del sombrero de copa. Es decir, de forma parecida a como aparece, en lo que respecta al busto, Terin con traje ibicenco, uno de sus mejores lienzos, y donde el sombrero subraya la atrayente personalidad del representado, en este caso por propia y libre elección de éste (tal como nos comunica L. Llobet, testigo del oportuno posado).

Ateniéndonos al momento en que se realizó, este óleo sería ya producto del que se ha descrito como un regionalismo crepuscular, teñido a veces de melancolía (Pérez Rojas y Alcaide 1998: 73) y enriquecido con el progreso artístico del autor, ya más 
interesado en otras inquietudes de composición y color; de «un color abierto a mil colores", en "una especie de evasión y de libertad, de grito", haciéndonos eco de sus propias palabras (en Aguilar 1998: 47).

En realidad —como hemos recogido en otra ocasión (Mateu Prats 2011a: 39)—, cuando Roca, siempre alejado intencionadamente de las corrientes de su época, acometió las series regionalistas, estos argumentos ya habían perdido gran parte de su vigor, auque continuaran dando frutos de calidad. Pero el desfase se haría innegable y casi insostenible al cruzar el umbral de la posguerra y extenderse hasta los cincuenta, corriendo el riesgo de derivar hacia una estética de calendario (Pérez Rojas y Alcaide 1998: 73).

Es también en este periodo en el que se ha venido datando L'bereu, tal vez especialmente en función de no haberse llegado nunca a finalizar, aunque su génesis tuviese lugar — como la práctica totalidad de las obras aquí mencionadas- en los preludios de la guerra civil, en conformidad con el valioso testimonio aportado por Luis Llobet Tur (2007: 25-26).

\section{EL CAPÍTULO SANGRIENTO DEL MUNDO TRADICIONAL Y LA GUERRA CIVIL}

Según la prensa local, fue en la primavera de 1936 cuando Amadeo Roca volvió a $\mathrm{Ibiza}^{24}$, en lo que por entonces ya constituía uno de sus frecuentes viajes entre Madrid, París y la isla. En esta ocasión, ajeno a la gestación de los inminentes acontecimientos bélicos y suponemos que mayormente movido por el objetivo de concluir el lienzo sobre las reseñadas "Bodas" ibicencas —iniciado años atrás—, con vistas a su participación en el Salón de Independientes de París (Barragán 2008: 119). Sería también por entonces cuando comenzaría el cuadro de L’hereu, encontrando nuevamente en el pueblo de Sant Miquel dos modelos especialmente apropiados para encarnar esos dos arquetipos de la sociedad isleña: la madre anciana, que en su día -contemplando la posibilidad de sobrevivir a su futuro marido- pactó que se le permitiera seguir viviendo en la casa patriarcal bajo la administración del hijo designado como principal heredero. Y éste último, por lo regular el varón primogénito, con el consiguiente sentimiento de superioridad y poder (Alarco von Perfall 1981: 88-90, 154-157).

Curiosamente, el perfil psicológico del joven elegido por Roca para representar esa figura tan significativa del derecho foral ibicenco, habría resultado igualmente válido para hacer lo propio con el del llamado "verro" entre los payeses. Aludiéndose con ello -intentando ofrecer una descripción aproximada ${ }^{25}$ - a la peligrosa conjugación de bravura, pasión y amor propio que, íntimamente vinculada al uso de las armas, era determinante en los frecuentes desenlaces sangrientos del festeig o cortejo tradi-

\footnotetext{
${ }^{24}$ Con fecha 6 de abril de 1936, el Diario de Ibiza anunciaba su llegada, procedente de Alicante. El 2 de junio de ese mismo año aún se encontraba trabajando en el cuadro "para llevarlo a la Exposición de París, pensionado por la Diputación y Ayuntamiento de Valencia" (Anónimo 1936a: 4; Anónimo 1936b: 2, respectivamente).

25 Según la definición recogida en el DCVB de Alcover y Moll (ed. electrònica 2001-2002): "Verro...4. Home que presumeix de valent, de molt fort (Eiv); cast. matón. Es verro d'es poble: el valent o dominador del poble (Eiv). También: "...5. Terrible, cruel (Eiv). 'Aquest mal és més verro'”; (dcvb.iecat.net/, fecha de acceso: 9-11-2011).
} 
cional. Y así, el descubrimiento en un camino de un joven apuñalado y con la cabeza destrozada por una gran piedra, trajo consigo que Amadeo Roca no pudiera seguir teniendo como modelo al que se confesó culpable del crimen. Hacía tiempo que la víctima y el asesino cortejaban a la misma at.lota, de casa acomodada, y el drama sobrevino después de haberse anunciado con el intercambio de insultos y amenazas entre ambos pretendientes (Llobet Tur 2007: 26-27).

En una inquietante cadena de adversidades, a la conmoción del pueblo por esa muerte siguieron los primeros conatos de la Guerra Civil, pudiendo ver Amadeo Roca con horror cómo su paraíso ibicenco se iba convirtiendo paulatinamente en un auténtico infierno, donde se producían toda clase de abusos, crímenes y venganzas (Barragán 1998: 121). Precisamente la iglesia en la que vendría dando las últimas pinceladas a las referidas "Bodas" se intuía como uno de los objetivos más vulnerables, pese a su carácter de fortaleza. Y si para poner a resguardo el estandarte parroquial, alguna mujer procedió a ocultarlo como faldellí o refajo bajo su gonella; el propio Amadeo Roca pudo idear algún otro recurso para resguardar su obra, así como la identidad de las personas allí representadas (información oral de Torres Peters y Llobet Tur).

Ese deseo por proteger la identidad de los que allí se mostraban se concretaba muy especialmente en ciertos personajes representativos, o de importante papel social en el pueblo de Sant Miquel, que podrían aparecer en actitud de asistir al enlace. Es decir, evocando la manera en que ha venido ocurriendo en la historia de la pintura con la intromisión en la escena de la figura del donante o donantes, manifestando públicamente su poder y propia religiosidad. Factores, todos ellos, que habrían incidido en la decisión tomada por Amadeo Roca de quemar ese fragmento en particular (destrucción que erróneamente haría pensar que había afectado a la totalidad del lienzo).

Tanto de acuerdo con Luis Llobet, como con Vicente Ripoll (hijo de la que fuera la modelo preferida de Amadeo Roca) y alguna otra persona de Sant Miquel, fue el mismo Roca el que se encargó de fragmentar el cuadro; fragmentos que en el resto de los casos enrollaría cuidadosamente y, al menos en su mayor parte, ocultaría en un pajar, con la colaboración de algunos vecinos. Mientras él, por su parte, ayudaba a los de Santa Eulalia a salvar la custodia y algunas imágenes de este otro templo parroquial (Planells Cardona 2008: 340), antes de embarcar hacia Valencia.

Según continúa informándonos L. Llobet, entre el conjunto de lienzos y dibujos que constituyeron su único equipaje se contaría uno de los fragmentos de las Bodas de Ibiza (el único que hoy se conoce), así como la inacabada obra L'bereu, cuyo modelo ya habría sido detenido y encarcelado tras la confesión del crimen, por más que la llegada de los milicianos conllevara su liberación y posterior fuga de la isla, en una barca de bou o pesca, con el mismo destino que ya había emprendido A. Roca. Allí se personaría en el propio domicilio del pintor, solicitándole ayuda económica para desplazarse a Francia (Llobet Tur 2007: 26), poco antes de que éste saliera a su vez de España.

Sin abordar las vicisitudes que depararía a Roca su huida a ese país (pasando antes por Roma y Florencia ${ }^{26}$ ), resulta significativo constatar cómo fue una coleccionista de arte que había conocido en Ibiza (la señora Salzmann), quien en Suiza le prestaría

\footnotetext{
${ }^{26}$ Información nuevamente aportada por L. Llobet Tur.
} 
ayuda, tanto moral como económica, y a la que, al llegar finalmente a París, Amadeo Roca correspondería con uno de sus dibujos de ibicencas (Barragán 1998: 121).

La consagración que como pintor llegó allí a alcanzar no fue suficiente estímulo para retenerle y, cuando regresó a España, se encontró con un panorama desolador, a todos los niveles. En el profesional que aquí tratamos, los bombardeos sobre la Ciudad Universitaria de Madrid habían destruido la Casa de Velázquez, donde tenía la totalidad de las obras que, como pensionado, había realizado para esa institución francesa. (Barragán 1998: 125). Y en Ibiza, según se dice, su producción artística también habría desaparecido. Si bien, el hecho de que fuera el mismo Roca el encargado de fraccionar su grandiosa obra Bodas de Ibiza, en lugar de ser dicha mutilación o "destrozo" una consecuencia más de la guerra — tal como se ha venido suponiendo- - permite que podamos concebir una cierta aunque lejana esperanza sobre la recuperación, algún día, de otra parte o partes de este magnífico cuadro.

\section{HIPOTÉTICA RECONSTRUCCIÓN COMPOSITIVA DE BODAS DE IBIZA}

La escena que, al menos por el momento, tenemos ocasión de contemplar (de $257 \times$ $78 \mathrm{~cm})^{27}$ nos muestra al fondo el aludido estandarte parroquial (sin que lo enarbole ninguna mujer, como se mencionaba en las reseñas periodísticas) y, en primer término, a un grupo de tres muchachas de distinta edad (en vez de una) que asisten serenas y engalanadas con sus mejores gonelles de color al enlace. Son precisamente las propiedades decorativas de este tipo de indumentaria las que —como aducíamos anteriormente- en buena parte definen la identidad artística de Roca en el campo costumbrista, o, en palabras de Pérez Rojas y Alcaide (1998: 75), del regionalismo dulcificado que practicó. Aunque incluso la correspondencia con el natural de esos tejidos parezca que también fue cuestionada en Ibiza ${ }^{28}$.

Lamentablemente, de la figura que representaría a la novia únicamente se aprecia una mínima parte de su contorno derecho. Suficiente, sin embargo, para poder reconocerla vestida con la antigua gonella negra, prácticamente como ya la veíamos dibujada por Roca en una de sus primeras obras ibicencas (¿1931?), y tal como asimismo aparece en la referida fotografía (figs 2 y 6). Con ello, si nos atenemos a las señaladas notas de prensa, se asociaría diacrónicamente con las jóvenes vestidas con las posteriores gonelles de color, aunque lo hiciera sincrónicamente con el atuendo del hombre con quien figuraba casarse, así como con los acompañantes masculinos de aquel.

Recordemos que sobre el aspecto indumentario de los hombres se decía que todos iban con el traje del siglo XIX (configurado por calçons de punxa, camisa de "mostra", jupetí con botonadura colgante en sus hojas delanteras y espardenyes "de morret.), sin especificarse barret para ninguno de ellos, tal como era preceptivo en el interior del recinto sagrado; a diferencia del novio que, aún sin llevar chaqueta o jaquetó, se cubría indebidamente con sombrero de copa. Una configuración indumen-

\footnotetext{
${ }^{27}$ Además se conserva un trozo de pequeñas dimensiones (Barragán 2008: 125).

28 "Eso de llenar una tela de colorines a capricho del artista sin basarse en la realidad alguna, será muy bonito para un telón de guiñol; pero está muy lejos de reflejar las costumbres de un pueblo" (Planells Torres 1934b: 1).
} 
taria que, al menos en lo relativo a la chaqueta, subsanaría el pintor, según se desprende de la citada instantánea y por la conformidad que, en este aspecto, mostraría posteriormente el autor de las críticas periodísticas (Planells Torres 1935b: 2).

Teniendo en cuenta que - tal como se aludía también en ellas-, eran dos los personajes masculinos que acompañaban a los contrayentes (un hombre de edad madura y un "mozalbete"), podemos imaginar que equilibrarían la escena situándose al lado opuesto de las citadas mujeres, mostrándose tal vez también como aquellas básicamente de perfil, y dejando destacar en el centro a los novios protagonistas. Por otro lado, cabe también pensar que para compensar el peso visual que a su vez suponía el estandarte en un lateral del cuadro, en el otro se situaría la "larga pértiga semejante a una vara de camilla" que se decía llevaba el joven acompañante. Tal figura evoca, así, la de uno de los pastores que se muestran en la adoración al Niño pintada en el púlpito de la iglesia ibicenca de Sant Josep de sa Talaia (1763), por su parte con la habitual incursión diacrónica de trajes populares ${ }^{29}$.

Si los modelos indumentarios representados en las pinturas dieciochescas de ese púlpito, y en el análogo del pueblo de Sant Antoni, guardaban relación con la entrega de un llavero de plata que — como símbolo de posesión del hogar (Cea 2002: 105) - podía hacer el recién casado a su ya esposa "a faz del altar", en una de sus fórmulas de transmisión (Mateu Prats 2009: 91-105), Amadeo Roca optaría por los anillos nupciales para simbolizar el enlace (Planells Torres 1934a: 1). Aunque fuera un relicario de vidrieras, la "joia" de plata de mayor interés etnográfico que nos muestra en su mano el novio de esas Bodas de Ibiza en el que considerábamos un dibujo previo (fig. 4), posiblemente como otra opción para trasladar al lienzo.

FIG. 11. -Fragmento de "Bodas de Ibiza" (de $257 \times 78 \mathrm{~cm}$ ) conservado en el Museo de Bellas Artes de Valencia.

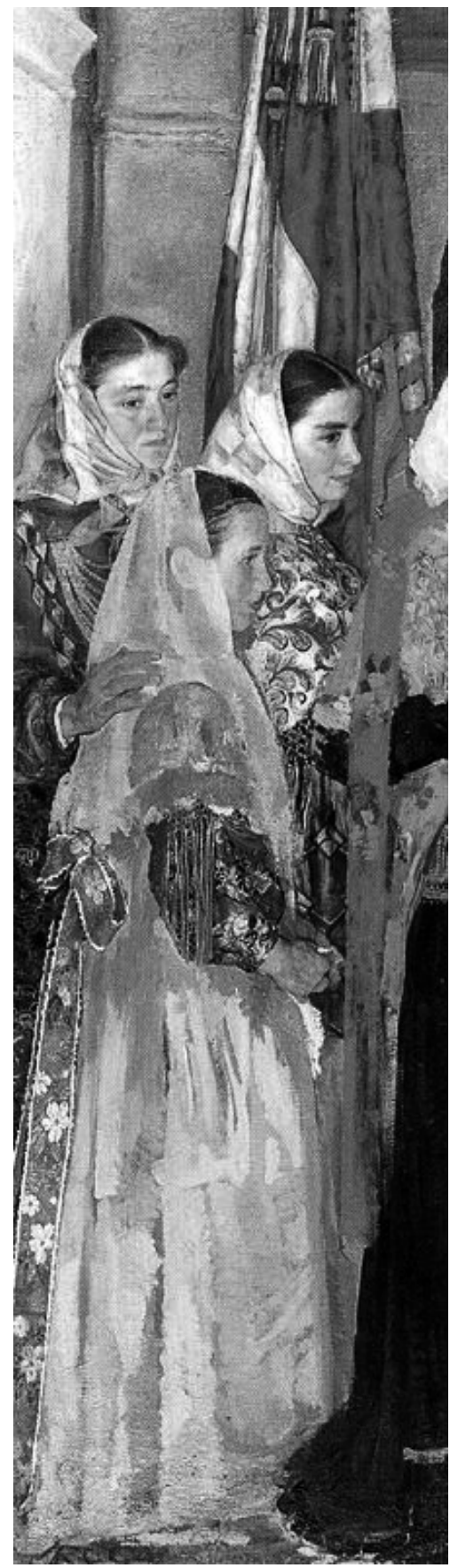

${ }^{29}$ Recordemos el valor que, dentro de las fuentes iconográficas, suele revestir el tema de $L a$ adoración de los pastores para el conocimiento de prendas populares. 
En lo referente al contexto religioso en que se ubica la escena, en la repetidas críticas se recriminaba que no apareciera sacerdote alguno bendiciendo la unión. Diciéndose, a propósito del interior del templo donde tenía lugar la ceremonia, que al fondo podía apreciarse la imagen de un santo sobre un pequeño altar. Es decir, sin que al parecer hubiera plasmado Roca el retablo de esa iglesia de Sant Miquel, que desaparecería poco más tarde con la Guerra Civil, sin dejar — según creemos- testimonios gráficos ${ }^{30}$. Huelga recalcar la doble importancia que revestiría la hipotética localización de los fragmentos desaparecidos de estas Bodas de Ibiza, si al final el pintor se hubiera decantado por reproducirlo (de modo análogo a como J. Llaverías captó el aspecto que aún presentaba en 1912 el interior de la iglesia de Sant Antoni antes de sufrir, a su vez, los efectos de la guerra y ciertas reformas).

Nos atrevemos a concebir ciertas esperanzas sobre esa posible localización del resto del cuadro, teniendo en cuenta los hallazgos que nosotros mismos hemos podido realizar de testimonios iconográficos que se daban en la isla por totalmente desaparecidos, cuando no se desconocía su propia existencia ${ }^{31}$. Y es que, por más que actualmente esté resurgiendo en Ibiza el interés investigador que se sintió en este campo de la etnografía a comienzos del siglo XX, han sido muchos los años en que, básicamente, se ha vivido de los frutos que se recogieron entonces. Una situación de estancamiento que, junto a la sistemática repetición de ciertos conceptos, ha traído consigo que simples instantáneas o realidades parciales del traje popular ascendieran a la mítica consideración de prácticamente perennes. Abriendo con ello, paradójicamente, la puerta a las descalificaciones hacia todos aquellos pasos encaminados a identificar los diversos estadios evolutivos de dicha manifestación a lo largo de su devenir histórico, tal como ya señalábamos en otro estudio (Mateu Prats 2003: 109-113, 135-141, 148).

\section{APRECIACIONES SOBRE EL VALOR DOCUMENTAL DE LA PRODUCCIÓN DE AMADEO ROCA}

Unas circunstancias equiparables debieron confluir en las reprobaciones que tuvieron como diana la producción pictórico-etnográfica de Amadeo Roca en la isla, probablemente fundamentadas en el aspecto novedoso que - como licencia artística o nosuponía su interpretación o visión del costumbrismo isleño, con respecto al repetitivo repertorio existente. Así como susceptible de poder considerarse —al menos desde una

\footnotetext{
${ }^{30}$ Información facilitada por F. X. Torres i Peters, en su doble condición de investigador y Delegado Diocesano del Patrimonio Eclesiástico de Ibiza y Formentera.

${ }^{31}$ Es por ejemplo el caso de un valioso y significativo documento para el estudio de la indumentaria tradicional llevada en Ibiza (concretamente un fragmento del citado púlpito de Sant Antoni de Portmany, de 1769) (Véase Mateu Prats 2009: 91-105). Mientras que del propio desconocimiento son una muestra las acuarelas de la Escuela Madrileña de Cerámica, realizadas en los años treinta del s. XX (Mateu Prats 2001 y 2010: 35, 37) y la producción igualmente isleña de diversos pintores a su vez interesados por esta temática, como Santiago Martínez (uno de los discípulos predilectos de Sorolla) o Ismael Blat. Por otra parte, gracias a las informaciones aportadas por F. X. Torres Peters y M. Davies hemos tenido la primicia de estudiar las recién descubiertas pinturas de la iglesia de Sant Miquel y los grabados de J. Cambessedes, en ambos casos correspondientes a los trajes populares de principios del siglo XIX (Mateu Prats 2012b: 138)
} 
particular y limitada perspectiva- potencialmente peligroso para los intereses turísti$\cos ^{32}$. Si es que no incidieron negativamente también — como lamentablemente suele ocurrir y nos inclinamos a pensar- ciertos factores de índole personal.

A todo ello hay que añadir el sentimiento de inferioridad que por estos años se había propagado en la propia payesía, al vincular el concepto de incultura o atraso con la continuidad de ciertas prácticas tradicionales, como era la conservación del traje típico, abandonado ya por los hombres pero aún con vigencia social entre muchas mujeres. La situación desembocaría en una fuerte controversia, reflejada en la prensa isleña, entre los partidarios del abandono de la indumentaria tradicional y los que defendían su conservación, en algunos casos bajo una perspectiva digna de encomio, pero en otros limitándose a una empobrecida, rígida y fosilizada normativa. Esto es, alejada de la flexibilidad que había acompañado la evolución natural de esta manifestación popular en el pasado.

En este contexto, y particularmente en el correspondiente a esos primeros defensores del traje, se inserta la halagadora equiparación gestual de la payesa ibicenca con la "Gioconda", como una de las diversas evocaciones que sugería su recatada o decorosa imagen tradicional a personajes de un representativo nivel cultural, como el ibicenco José Costa "Picarol" (1931: 1). Tal evocación fue compartida o secundada por Amadeo Roca con los pinceles, en una obra que a su vez reviste un importante valor documental por la plasmación de las prácticamente olvidadas "agustinades", o vueltas de coral, que habrían llegado a las manos del pintor — como fruto de una directa o indirecta búsqueda etnográfica- cuando se difundieron las críticas a sus Bodas de Ibiza.

Quien así lo hizo sin haber contemplado ni siquiera directamente ese cuadro - haciéndose simple eco de lo que manifestaba le habían dicho—, no ponía sin embargo objeción alguna a la plasmación de determinados elementos o detalles, que actualmente son motivo de controversia e incluso de negación, a causa del progresivo olvido con que ha continuado empobreciéndose la información oral sobre este aspecto de la cultura material ibicenca. Nos referimos en particular al uso del sombrero de copa y de las espardenyes de morret o "morrillo" — cerradas en la puntera-, por el hombre de la payesía (Planells Torres $1934 \mathrm{a}$ y b: 1 y 2). Asimismo, el hecho de que esa crítica no se basara en una observación directa, sino en la fiabilidad u honradez que se atribuía reiteradamente a informantes anónimos, ha de tenerse muy presente a la hora de calibrar el valor de la descripción que el articulista ofrece sobre la composición original de esa obra, y que dice luego rectificada por el pintor. No hay así en ningún momento quien se responsabilice de los ataques contra las supuestas aberraciones costumbristas de Amadeo Roca.

\footnotetext{
${ }^{32}$ Esto es, como ya se había temido años atrás para la imagen tradicional de la isla proyectada desde distintos ángulos literarios por otros dos valencianos, como Víctor Navarro (1901) o Vicente Blasco Ibáñez (1908), aunque no faltara quien alzara la voz en su defensa. En realidad, aún reconociendo la existencia de algunas incorrecciones en el estudio y novela de carácter costumbrista de uno y otro autor, ninguna de ellas podría justificar la exacerbada repulsa que despertaron entre un nutrido de ibicencos, tendentes a no reconocerse en la imagen que, sobre este aspecto de la isla, recogían y proyectaban "els forasters" (salvo excepciones como la del Archiduque Luis Salvador). Especialmente, por los años que tratamos, en lo que atañe a los frecuentes homicidios que proseguían causando las rivalidades pasionales del festeig tradicional, como tuvo ocasión de comprobar el propio A. Roca. Se trataba de un problema reconocido a nivel interno pero prácticamente tabú de cara al exterior.
} 
En todo caso, parece que A. Roca se mantuvo elegantemente al margen de la polémica, aunque le afectara notablemente. Así se recogía en otro diario de la isla (Riera 1935a: 2), junto con una valiosa información sobre los criterios etnográficos seguidos por el artista en la elaboración de esas Bodas de Ibiza, trasluciendo en este caso un profundo y afectuoso respeto hacia su persona y obra.

Después de rememorar brevemente el éxito alcanzado en París con su óleo sobre Los lagarteranos, se decía que el pintor había llegado a la isla atraído por las bellas leyendas que la envolvían y con el interés de estudiar sus figuras típicas. Teniendo para esto último en cuenta el proceso evolutivo que sufre el traje en sus diversos tiempos, pues — según se alegaba-, aunque fueran muchos los lienzos donde tales figuras podían verse reproducidas, ninguno o casi ninguno expresaba fielmente la autenticidad por él buscada. Por este motivo, se había embarcado en el difícil proyecto de buscar, indagar, preguntar..., intentando contrarrestar la "carencia de datos" existente sobre una u otra "modificación" indumentaria, "todo para la pureza de su obra en inspiración" (Riera 1935a: 2). Esta consideración se refuerza teniendo en cuenta el aludido asesoramiento etnográfico y — prácticamente con toda seguridad aportación incluso de prendas- que recibió de Antonio Marí Ribas "Portmany" —en conformidad con A. García Ninet-, así como de algún otro entendido informante isleño ${ }^{33}$.

Consecuentemente, las recriminaciones que se habían hecho al pintor apenas iniciada su labor artística no eran para este otro ibicenco sino "dardos calumniosos", en un "ataque inesperado y exento de toda razón", llegando a manifestar, ante la contemplación del lienzo ya por entonces prácticamente finalizado, que la espiritualización de las mujeres campesinas que se mostraban ${ }^{34}$, le hacía pensar que "si los señores instigadores de aquella campaña admirasen unos momentos el cuadro", sus "lenguas de víbora" perderían la eficacia del veneno ante el amor y la belleza que de él se desprendían. Era notorio - proseguía alegando- que en los corazones nobles como el de Roca no anidaba el rencor, elevándose su alma con el perdón de las injurias, pues toda alma elevada, como la que él tenía, estaba hecha de exquisiteces y refinamientos, como una gran armonía de la Naturaleza. Y así — según concluía- Amadeo Roca continuaba trabajando en el pueblo de Sant Miquel "para luego mostrar al Mundo del Arte un jirón de Ibiza; el alma del 'payés' y 'payesa', que era la propia alma de la isla, donde la fina sensibilidad del artista descubría cada día nuevas bellezas, nuevos horizontes... (Ibidem).

33 Tal como ya señalaba en otra ocasión (Mateu Prats 2011a: 39), sería el propio Amadeo Roca el veterano pintor a quien yo misma tuve ocasión de visitar en los años ochenta en su prestigioso estudio de Madrid, y quien a propósito me comentó su interés por este aspecto tan reseñable del costumbrismo ibicenco. Según rememoraba, había sido una señora de la Marina, profunda conocedora del tema, quien en muchas ocasiones le había guiado en el difícil camino de la corrección indumentaria, con precisas indicaciones sobre trajes y joyas. Pudiendo reconocer yo con asombro en su nombre y señas (Isabel Escandell Ferrer) a mi propia bisabuela materna, a la que por mi parte debo la transmisión de análogos conocimientos. Posiblemente ella misma mantuvo también contacto con A. Marí Ribas "Portmany" (véase la nota 39), dada la relación que sabemos sostuvo éste con su propio hijo (mi abuelo) Bartolomé Prats, y que prosiguió con el correspondiente núcleo familiar

${ }^{34}$ Con ello se hacía eco de lo ya manifestado en el Diario de Ibiza: "...en la nueva obra, que será expuesta en el Salón de Primavera de París, demuestra el Sr. Roca conocer divinamente la espiritualidad de los ibicencos" (Anónino 1935a: 1). 
Sin extendernos en la transcripción de las crónicas que se sucedieron, baste decir que quien en su día arremetió contra Roca con tanta aspereza, no tendría finalmente sino que rendirse ante "una gran obra de arte", tal como encabezaría la última de sus reseñas (Planells Torres 1935b: 2.). Por más que lo hiciera tras haber intentado justificar con la ironía anteriores reproches, así como mantenerse en cierta manera contrario al diacronismo que mostraban en su indumentaria los hombres y mujeres plasmados por el pintor valenciano ${ }^{35}$. Un diacronismo, en todo caso, que tal como también acababa de algún modo por reconocer, se habría suavizado o armonizado entre los dos sexos, tras una rectificación por parte del pintor ${ }^{36}$.

\section{EL SELLO DISTINTIVO DE ROCA EN LA PINTURA COSTUMBRISTA}

Estas serían, afortunadamente, las últimas opiniones sobre su arte que Roca se llevaría como equipaje inmaterial al tener que abandonar la isla cuando estalló la guerra, tan sólo pocos meses después. Si bien, el hecho de que para entonces ya se sintiera íntimamente unido a la isla, tanto personal como profesionalmente - habiendo participado incluso en alguna exposición local ${ }^{37}$-, haría que, pese a los diversos acontecimientos que posteriormente le irían alejando de sus costas —en esos claros y oscuros que fueron definiendo su trayectoria vital-, ya nunca se rompieran los lazos establecidos.

De esta forma se comprueba, por ejemplo, a través del amistoso contacto que siempre mantuvo con la familia Llobet-Tur de Montis, uno de los linajes más emblemáticos de la ciudad amurallada de Ibiza (o Dalt Vila), y origen también del renombrado pintor Mariano Tur de Montis. Fruto artístico de esta relación — que no iba en detrimento de la alta cotización de Roca- son los tres retratos que hiciera de Luis Llobet Tur, en uno de los cuales éste se muestra vestido al estilo de la payesía, como claro reflejo de su sentido ibicenquismo ${ }^{38}$. Si en este caso — de principios de la década de los 70 - , la inacabada o imprecisa factura del rostro, y propio volumen del cuerpo, no

\footnotetext{
35 "Nuestra opinión [...] es la de que el artista don Amadeo Roca, no precisa de lanzas de nadie que lo defiendan ya que mejor escudo y lanza que su paleta y su pincel, difícilmente han de dársele. Por lo tanto, siga pintando el señor ROCA sus tipos favoritos en ese placentero pueblo de San Miguel, que aunque mezcle los contemporáneos de Adán con los de Azaña no hemos de ser nosotros los que declaremos guerra a su arte, admirable en su técnica de dibujo y de colorido" (Planells Torres 1935a: 1).

${ }^{36}$ "Una gran obra de arte. Está dándosele los últimos retoques por el eximio pintor D. Amadeo Roca y es su escenario el pueblo de S. Miguel. Según nos ha dicho un señor de dicho pueblo, el Sr. ROCA, con muy buen criterio, ha variado en lo que toca a vestuario de los payeses que en el cuadro figuran apareciendo ahora más en armonía con los varones que también en el cuadro aparecen. 'Rectificar es de hombres sabios', y el Sr. Roca no ignora la máxima. Por esto ha rectificado. También vamos a rectificar nosotros; y lo que antes fue protesta, se tercia en elogio ahora. Y no dudamos que dicho cuadro le valdrá al artista D. Amadeo Roca muchos lauros" (Planells Torres 1935b: 2).

37 «...en el salón principal de Ebusus [...] Roca Gisbert (Amadeo). 47. Retrato de F. Mir, 48. El Estudiante. 49. Dibujo para grabado (Anónimo 1935b: 4).

${ }^{38}$ Otro retrato se reproduce en L. Llobet (2007: 28). En el tercer caso, es un apunte del rostro sumamente similar al que se muestra en el pintado al óleo, pero más certero en la captación de los rasgos faciales.
} 


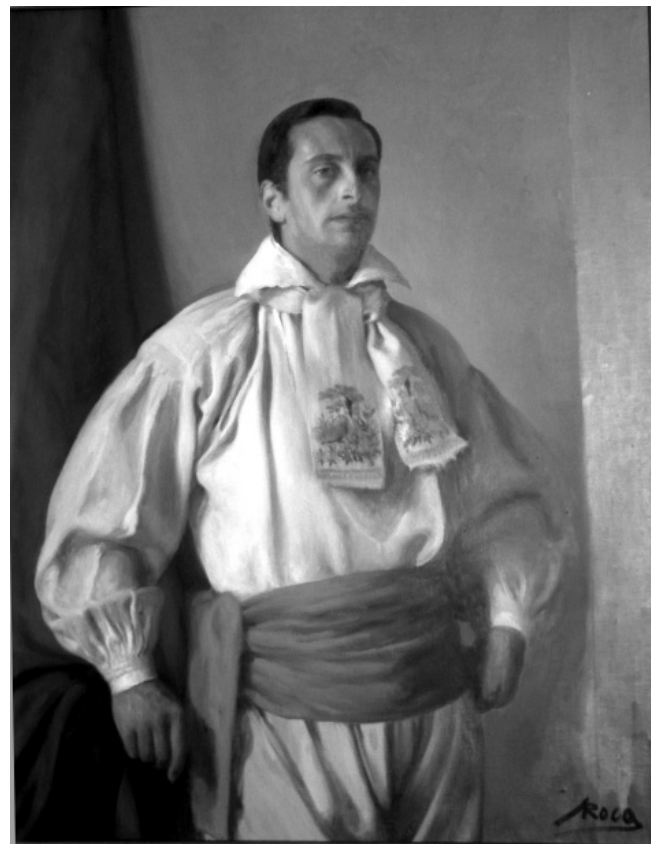

FIG. 12.-Luis Llobet Tur vestido al estilo de la payesía ibicenca y pose semejante a "L'hereu" ${ }^{40}$ (fig. 9), según retrato de Amadeo Roca (comienzos de los años 70). Gentileza de Luis Llobet Tur. hacen justicia al retratado, la indumentaria elegida sí deja en cambio singular testimonio de la xalina, o vistosa corbata que aquí vemos cayendo con las puntas abiertas sobre el pecho ${ }^{39}$ (por más que su asociación con la camisa de drap sea tal vez cuestionable). Una muestra del interés de la colección etnográfica que el pintor llegó a poseer, y que lamentablemente desaparecería en los últimos momentos de su vida.

La melancolía que ya decíamos se ha reconocido en este regionalismo crepuscular de Roca no impediría, sin embargo, que éste fuera abandonándolo, al tiempo que iba desarrollando otras inquietudes artísticas. Y así, aunque la figura humana continuara siendo su objetivo principal, se complacería especialmente en verano con la luz y sol de la isla para plasmar diferentes paisajes ${ }^{41}$, "como en una especie de vacación, de relax", "para limpiar la paleta", reproduciendo nuevamente sus mismas palabras (citado en Aguilar 1998: 47). Observándole como un asceta de la pintura, alejado de los circuitos comerciales y en

contacto con la naturaleza, José Ma Ballester recordaba, de acuerdo con Aristóteles, que la finalidad del arte era dar cuerpo a la esencia secreta de las cosas, no el copiar su mera apariencia (citado en Aguilar: 49-50). Tal como igualmente se refleja en sus retratos, con el ejercicio de penetración profunda que los caracteriza.

Esa misma sensibilidad para captar el "alma" o esencia —a que ya se refería su defensor ibicenco refiriéndose a la de la propia isla - la reconocerían también en la obra de Roca otros autores. Sus tipos de Lagartera o de Ibiza no son vistos así como una presencia folclórica más, sino como «una decantación del espíritu de aquellas tierras que, sin perder nada su realidad — trajes, adornos, relicarios...-, hacen de los mode-

${ }^{39}$ Se trata, precisamente, de la prenda que el propio Amadeo Roca me citó al evocar las conversaciones mantenidas al respecto con mi bisabuela por línea materna (véase nota 33), y que con casi total seguridad habría adquirido en su propio comercio, al igual que la camisa y algunas otras piezas — tales como las agustinades de coral- reflejadas en los lienzos comentados anteriormente.

40 "Al terminar mi retrato —escribe Luis Llobet refiriéndose al primero de los aludidos en la nota 38- me pidió que posara unas sesiones para terminar L'bereu, pero yo no daba el tipo. -Este cuadro nunca lo terminaré- me dijo. No podré encontrar un modelo como el que tuve en San Miguel" (Llobet Tur 2007: 26).

41 Véase a propósito Valero (2006). 
los elegidos personajes de gran dignidad, clasicismo y belleza". Hay una especie de elegancia intemporal y a veces, como en Bodas de Ibiza, un cierto hieratismo clásico a la manera de Giotto, y este es un aspecto que le diferencia de otros pintores que, al igual que él, tomaron el regionalismo, las costumbres populares o el folclore como temática de su obra (Aguilar y Seco 1998: 95).

Según el mismo Roca, "la capacidad para ver una cosa, para captarla y sentirla más profundamente", era la influencia del Oriente que los levantinos como él recibían del "horizonte enorme" que les daba el mar (Prada Junquera 1986: 45); la misma línea inmensa que podía contemplar desde las costas de Ibiza y que desearía siguiera unida a su producción artística, más allá de su propia muerte. Y es que su deseo — tal como manifestaba cuando ya tenía 78 años de edad- habría sido reunir su obra y sus objetos personales, de una manera "libre y con vida", en una pequeña casa, bien en la isla de Ibiza o en el pueblo valenciano de Manises que le vio crecer (Moreno 1984: 34). Una idea romántica ${ }^{42}$ que desafortunadamente para ambos lugares no llegaría a materializarse, en beneficio de su Valencia natal ${ }^{43}$.

En este sentido, y ya para finalizar, no podemos dejar de repetir el sentimiento contradictorio que ello nos produce, pues, tal como ya hemos señalado desde la perspectiva eminentemente ibicenca (Mateu Prats 2011a: 39), aunque la razón nos diga que tal vez fue mejor que no quedara su importante legado en nuestras manos -a la vista de lo que por ejemplo aún viene ocurriendo con el de L. Barrau-, con el corazón no podemos dejar de lamentarlo.

\section{BIBLIOGRAFÍA CITADA}

Aguilar, I. 1998. "La obra de Amadeo Roca a través de la crítica y la historiografía artística", en Amadeo Roca: 1-55. Valéncia: Generalitat Valenciana-Museu de Belles Arts de València.

Aguilar, I. y Seco, A. 1998. "Amadeo Roca. Diálogo entre tradición y técnica. Figuras y estampas", en Amadeo Roca: 86-100. Valéncia: Generalitat Valenciana-Museu de Belles Arts de València.

Alarco von Perfall, C. 1981. Cultura y personalidad en Ibiza. Madrid: Ed. Nacional.

Alcover, A. M. y Moll, F. de. 2001-2002: Diccionari català, valencià, balear. Ed. Moll-Institut d'Estudis Catalans. Edición electrónica dcvb.iecat.net.

\footnotetext{
${ }^{42}$ "En Agosto de 1982, Amadeo Roca, en una entrevista concedida en Ibiza a Concha García Campoy (Última Hora, 9 de agosto), comentaba lo siguiente: "Nos encontramos con una especial idiosincrasia a la española; el mero hecho de donar algo, hace sospechar al que recibe la donación que se está esperando algo a cambio y no se comprende que hay un sentimiento romántico y que lo que se pretende es que la obra mía y mis objetos de arte no queden dispersos; me gustaría verlos como deben estar. Pero entre la duda mía y la de los demás esto no se ha llevado a cabo y me interesa hacerlo porque el tiempo apremia. No quisiera que quedaran las cosas de cualquier forma amontonadas. Yo estoy capacitado para colocarlas" (en Aguilar 1998: 3).

43 A comienzos de 1997, el diario $A B C$ se hizo eco de la tesis doctoral escrita por J. A. Barragán sobre Amadeo Roca. "Semanas después, D. ${ }^{a}$ Consuelo Císcar Casabán, Directora General de Promoción Cultural, Museos y Bellas Artes de la Generalitat Valenciana, visita al pintor en su casa-estudio de la calle Claudio Coello de Madrid y se inician los trámites para la adquisición de toda su obra, que felizmente culmina apenas transcurridos unos meses. Estas obras tendrán pronto su ubicación definitiva en las Salas del Museo de Bellas Artes de Valencia", con lo que Amadeo Roca vería recompensada "toda una vida de sacrificios y trabajos magistralmente expresados a través del difícil arte de la pintura" (Barragán 1998: 145).
} 
Allen, P. 2006. The concept of woman, vol. 2: The Early Humaniste Reformation 1250-1500. Grand Rapids MI: W.B. Eerdmans Publishing. 1501.

Amades, J. 1936. Notes d'Indumentaria. Barcelona: Biblioteca de Tradicions Populars

Anónimo. 1884. "Sección local", La Isla (periódico semanal de Ibiza), 26-4-1884: 1.

Anónimo. 1904a. "En el Ayuntamiento". Diario de Ibiza 21-4-1904: 1.

Anónimo. 1904b. "Noticias locales". Diario de Ibiza 29-4-1904: 2.

Anónimo 1906a. "Los festejos". Diario de Ibiza 1-6-1906: 1.

Anónimo 1906b. "Festejos". El Agricultor 8-6-1906:1-2.

Anónimo 1934. "Gacetillas. En busca de antigüedades". La Voz de Ibiza 27-1-1934:2

Anónimo 1935a. "De San Miguel». Diario de Ibiza 23-1-1935: 1

Anónimo 1935b. "Dos exposiciones. El Arte y la Historia locales". Diario de Ibiza 6-8-1935:4.

Anónimo 1936a. "De viaje”. Diario de Ibiza 6-4-1936:4.

Anónimo 1936b. "De Arte". Diario de Ibiza 2-6-1936: 2.

Ballester, J. M. 1994. "Amadeo Roca: peintures, dessins, techniques mixtes", en Catálogo Exposición de la Casa de Velázquez. Madrid: Casa de Velázquez.

Barragán, A. J. 1998. "Biografía”, en Amadeo Roca: 101-145. Valéncia: Generalitat Valenciana-Museu de Belles Arts de València.

Blasco Ibáñez, V. 2007 [1908]. Los muertos mandan. Teddington, Middlesex: The Echo Library.

Bucovich, M. von, 1934. "Viatge a Eivissa", en Esplai. Il.lustració catalana: 383-384. Barcelona: Spes. Impr. Costa.

Canoa Galiana, J. 2006. "Lectura de los signos en Tres sombreros de copa", en Sigma 1992, 1 (Comunicaciones). Disponible en la Biblioteca Virtual Miguel de Cervantes.

Cea Gutiérrez, A. 2002. "La indumentaria en el refranero de Correas. Retrato y caricatura de la España del siglo XVII", en V. A., Moda y Sociedad. La indumentaria: Estética y poder: 101-132. Granada: Universidad de Granada.

Claessens E. A., 1858. Dos hojas de historia, ó sean rasgos de la conquista ultima de Ibiza. Ibiza: Impremta J. Cirer I Miramon.

Flores, A. 1861. "La ofrenda de los payeses". Crónica del viaje de sus Majestades y Altezas Reales a las Islas Baleares, Cataluña y Aragón en 1860. Escritas de orden de su Majestad la Reina. Madrid: Imprenta y Estereotipia M. Rivadeneyra.

Luis Salvador, Archique. 1982. Las Antiguas Pitiusas. Ibiza: Caixa de Balears Sa Nostra.

Llobet Tur, L., 2003. Antología literaria. Ibiza, s. XIX. Valencia: Artegraf Impressors

Llobet Tur, L., 2007. Unas páginas del pasado de Dalt Vila. Ibiza. Valencia: Artegraf Impressors.

Marí Cardona, J. 1984. Balansat. Eivissa: Institut d'Estudis Eivissencs.

Martínez García, A., 2006. "La Mona Lisa: un compendio de Medicina Interna". Anales de Medicina Interna 3: 139-141.

Mateu Prats, Ma L. 2001. "Escola de Ceràmica de Madrid", en Enciclopèdia d'Eivissa i Formentera. Vol. V. Eivissa: Consell Insular d'Eivissa i Formentera. Disponible también en www.eif.es

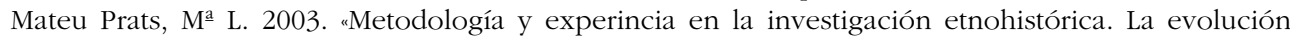
de las gonelles en Ibiza". Revista de Dialectología y Tradiciones Populares LVIII, 1: 85-102.

Mateu Prats, Maㅗ L. 2009. Gonelles y Joies en Ibiza y Formentera. Aproximación a sus paralelismos en el Mediterráneo (siglos XVII-XX). Colección Premio Vuit d'Agost. Ibiza: Consell d'Eivissa - Sa Nostra.

Mateu Prats Ma L. 2010. "Las acuarelas de un sueño educativo. (Una expedición costumbrista)", en La miranda (suplemento cultural del Diario de Ibiza) 17-12-2010: 35 y 37.

Mateu Prats, Ma L. 2011a. "Amadeo Roca y el mundo tradicional ibicenco" en La miranda (suplemento cultural del Diario de Ibiza) 3-6-2011: 37-39. Disponible también en www.diariodeibiza.es/ pitiuses.../06/...amadeo-roca/486293.html y blogdiariodeibiza.es/.../las-pinturas-ibicencas-de-amadeorocal

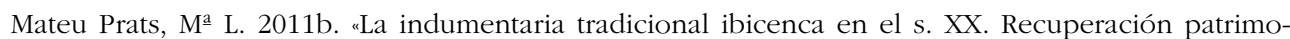
nial del pasado y progresiva pérdida de implantación social”. Revista de Folklore 356: 21-51. Disponible también en www.funjdiaz.net/folklore/07ficha.cfm?id=2669

Mateu Prats, Ma L. 2012a. "La participació eivissenca, de la mà del mestre Albert, en l'exposició del 'Traje Regional' a Madrid (1925)”. Eivissa 52: 72 (316) - 81 (325). 


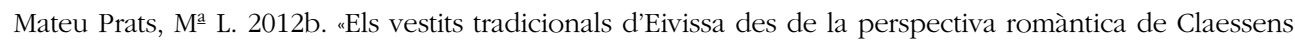
de Jongte (1858).. El Pitiús 2013: 134-142.

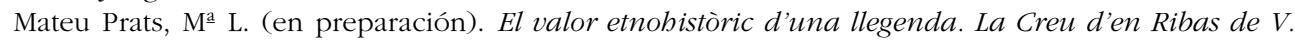
Ferrer Saldaña (1868).

Moreno 1984. "Amadeo Roca: 'A través del modelo, el arte es dinámico'”. ABC 21-7:34.

Navarro, V. 1901. Costumbres en las Pithiusas. Madrid: Imprenta del Asilo de Huérfanos del Sagrado Corazón de Jesús.

Ortiz Echagüe, J. 1971. España. Tipos y Trajes. Madrid: Publicaciones Ortiz Echagüe. (12a edición).

Pérez Rojas, F. J. y Alcaide, J. L. 1998. "Amadeo Roca. Pintor e ilustrador. Temática regionalista", en Amadeo Roca: 73-78. Valéncia: Generalitat Valenciana-Museu de Belles Arts de València.

"Picarol" (Costa Ferrer, J.). 1931. "Pro Turismo". La Voz de Ibiza 3-7-1931: 1.

Planells Cardona, M. 2008. "Roca Gisbert, Amadeu”, en la Enciclopèdia d'Eivissa i Formentera. Vol. 10: 339-340. Eivissa: Consell d'Eivissa.

Planells Torres, 1934a. "El Arte y el Absurdo I". La Voz de Ibiza 6-1-1934: 1-2.

Planells Torres, A., 1934b.»El Arte y el Absurdo II”. La Voz de Ibiza 8-1-1934:1-2.

Planells Torres, A., 1934c. "Nuestros Artistas". La Voz de Ibiza 19-10-1934:1.

Planells Torres, A.1935a. "Al paso de una arremetida". La Voz de Ibiza 30-3-1935: 1.

Planells Torres, A., 1935b. “Una gran obra de arte». La Voz de Ibiza 4-4-1935: 2.

Prada Junquera, M., 1986: “Entrevista en profundidad al artista Amadeo Roca Gisbert”. Correo del Arte 35: $20-23$.

Riera, J. La. 1935a. “Ibiza y el pintor español Roca”. Diario de Ibiza 26-3-1935: 2.

Riera, J. La. 1935b. “Carta abierta a D. Antonio Planells Torres”. Diario de Ibiza 2-4-1935: 3.

Román Calvet, J. 1906. Los nombres e importancia arqueológica de las Islas Pithyusas. Barcelona: Tipografía L'Avenc.

Sa Nostra. Caixa de Balears 1996a. Narcís Puget 1874-1960. Palma de Mallorca: Obra Social i Cultural "Sa Nostra".

Sa Nostra. Caixa de Balears 1996b. Laureà Barrau. Palma de Mallorca: Obra Social i Cultural «Sa Nostra".

Valero, V. 2006. "El caso Bucovich". Diario de Ibiza 14-1-2006: 25, 28-29.

Verdera, J. 1925. “Información”. Diario de Ibiza 9-9-1925: 2. 